\title{
Correction to: An organ of equilibrium in deep-sea isopods revealed: the statocyst of Macrostylidae (Crustacea, Peracarida, Janiroidea)
}

\author{
Simon Bober $^{1}$ (D) Torben Riehl ${ }^{2} \cdot$ Angelika Brandt $^{2}$
}

Published online: 4 November 2017

(C) Springer-Verlag GmbH Germany 2017

\section{Correction to: Zoomorphology \\ DOI 10.1007/s00435-017-0376-5}

Unfortunately, Table 1 was incorrectly published in the original version and the same is corrected here in this erratum. The original article was corrected.

The online version of the original article can be found under doi:10.1007/s00435-017-0376-5.

Simon Bober

simon.bober@yahoo.de

1 Centre of Natural History (CeNak), Zoological Museum, University of Hamburg, Hamburg, Germany

2 Department Marine Zoology, Crustacea, Senckenberg

Research Institute and Natural History Museum,

Senckenberganlage 25, 60325 Frankfurt, Germany 


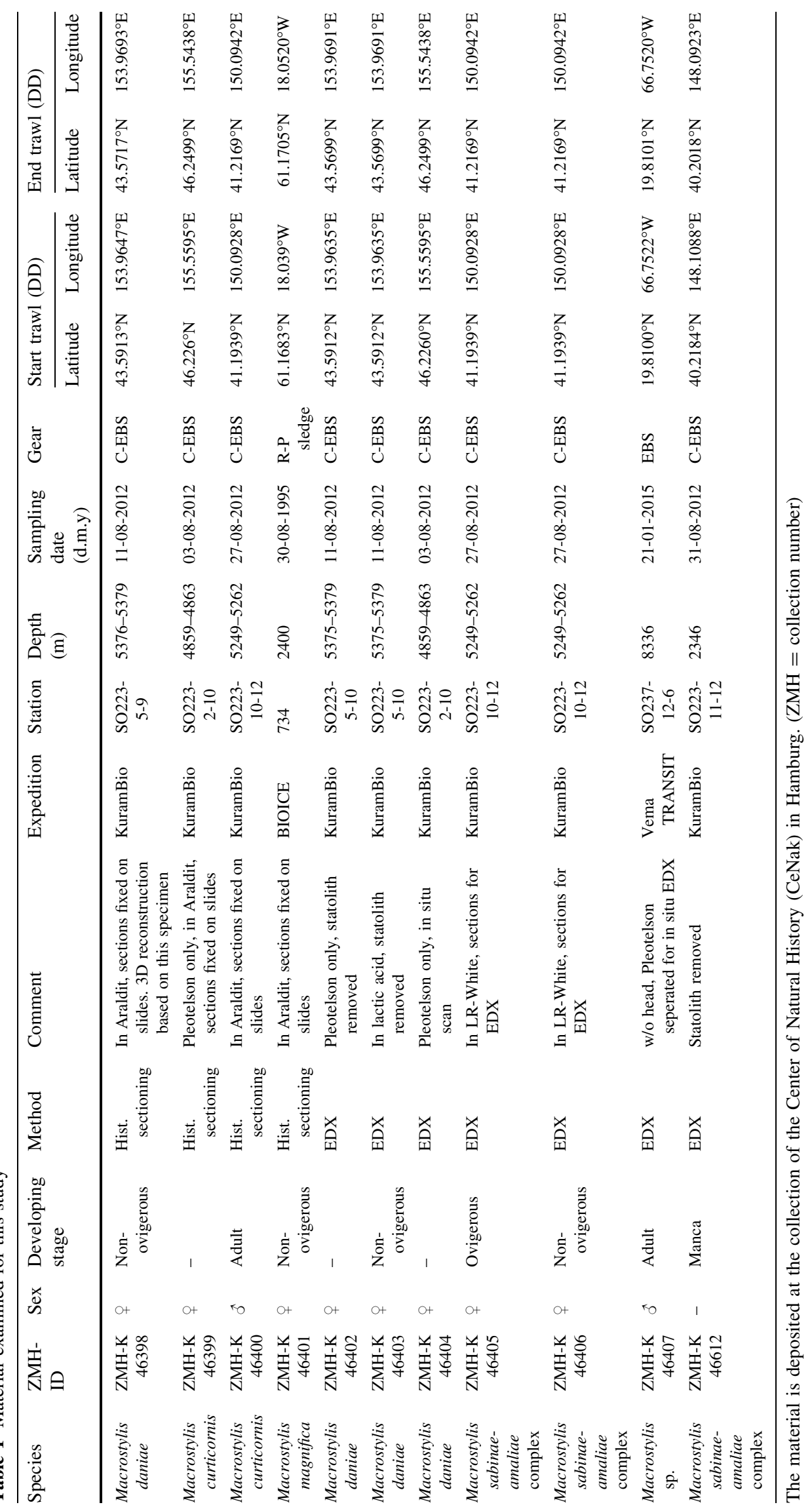

